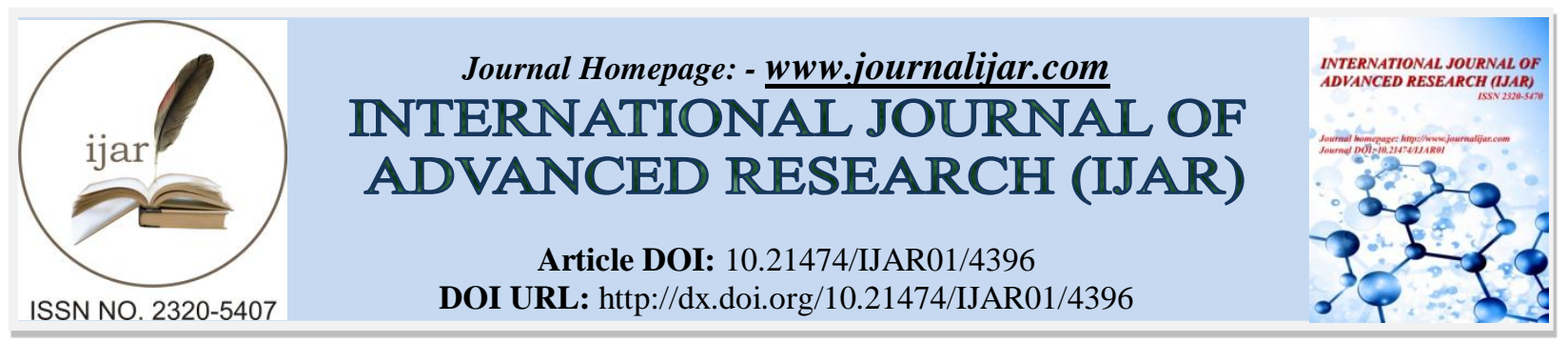

RESEARCH ARTICLE

\title{
EFFECTIVENESS OF LOW INTENSITY PULSED ULTRASOUND (LIPUS) IN ACCELERATING ORTHODONTIC TOOTH MOVEMENT.
}

Dr Dhirendra K Giri.

Department of Periodontology, Nobel Medical College Teaching Hospital, Biratnagar, Nepal.

\section{Manuscript Info}

\section{Manuscript History}

Received: 05 april 2017

Final Accepted: 07 june 2017

Published: june 2017

Key words:-

LIPUS, orthodontic tooth movement, treatment duration, ultrasound

\section{Abstract}

Background: Ultrasound in the form of low intensity pulsed ultrasound (LIPUS) has found various applications in medical therapies including bone healing. Orthodontic tooth movement is a lengthy procedure owing to the slow process of bone remodelling. Various pharmacological aids have been utilized in accelerating this tooth movement.

Aim: This study was designed to evaluate the effectiveness of LIPUS in accelerating orthodontic tooth movement.

Material and Methods: This case-control study was conducted on thirty young adults undergoing orthodontic treatment. LIPUS was applied to the right maxillary quadrant at two week intervals whereas the left maxillary quadrant was considered as control. The amount of space closure was measured at the beginning of treatment, one month and three months after beginning of treatment. Data was entered in excel sheet and statistical analysis done.

Results: LIPUS showed a significant acceleration in orthodontic tooth movement when compared to non-treatment side.

Conclusion: LIPUS can be used as an effective tool in reducing the duration of orthodontic treatment by accelerating the rate of tooth movement.

Copy Right, IJAR, 2017,. All rights reserved.

\section{Introduction:-}

Orthodontic treatment is one of the routinely performed therapeutic procedures in dentistry. This treatment comprises mainly of fixed appliances which are attached on the teeth and various types of tooth movements are carried out with the help of various wire configurations. ${ }^{1}$ The orthodontic treatment is based on the premise that when force is delivered to a tooth and thereby transmitted to the adjacent investing tissues, certain mechanical, chemical and cellular events take place within these tissues which allow for structural alterations and contribute to the movement of that tooth. ${ }^{2}$ This requires the use of application of optimal orthodontic force which can bring about the maximum tooth movement with minimum irreversible damage to the root, periodontal ligament and alveolar bone. ${ }^{3}$ Since the application of force is limited various other modalities have been applied to accelerate this tooth movement. Various pharmacological aids have been used to accelerate the orthodontic tooth movement like prostaglandins, $1,25(\mathrm{OH})_{2} \mathrm{D}_{3}$ (active form of Vitamin D), steroids etc. ${ }^{4,5}$ Recently electric stimulation and ultrasound application have also been tried in improving the tooth improvement. ${ }^{6,7}$ 
Ultrasound is a form of mechanical energy. Mechanical vibrations at 'increasing frequencies' is known as sound energy. The normal human sound range is from $16 \mathrm{~Hz}$ to something 20,000 Hz. Beyond this upper limit the mechanical vibration is known as ultrasound. The frequencies used in therapy are typically between $1 \mathrm{and}^{3 \mathrm{~Hz}}{ }^{8}$ Ultrasound therapy has also been demonstrated to stimulate growth factors, up-regulate bone proteins, and increase specifically the production of vascular endothelial growth factor (VEGF); these effects play an essential role in the maintenance and repair of dental tissues, osteoclast differentiation, bone resorption, and possibly the dentine -pulp complex. ${ }^{9}$ It is worth noting that because protein molecules absorb ultrasound energy at different rates; collagenous tissues can be targeted directly and preferentially, enhancing precision of ultrasonic applications. ${ }^{10}$ This makes ultrasound a novel candidate for the stimulation of dentine regeneration and a variety of other therapeutic dental applications. The application of ultrasound energy at much lower levels than is the current clinical norm is starting to gain ground as a therapeutic possibility. ${ }^{11}$ Low intensity pulsed ultrasound (LIPUS) is clearly ultrasound energy, but delivered at much lower intensity than traditional ultrasound energy. There are other differences with the output of LIPUS devices but, this is the most obvious issue. While a typical therapy machine will offer an operating frequency choices of $1 \mathrm{MHz}$ or $3 \mathrm{MHz}$, the LIPUS operating frequency at a $0.75 \mathrm{MHz}$ frequency. ${ }^{12}$

LIPUS treatment has been shown in various experimental studies to accelerate the restoration of mechanical properties of bone, such as maximum torque and torsional stiffness during fracture healing ${ }^{13,14}$ It was shown that ultrasound accelerated fracture healing when applied during the inflammatory and early proliferative phases of bone regeneration. However, when applied in the late proliferative phase, it stimulated cartilage growth, suggesting that the time of application is important. ${ }^{15}$ Many in vivo studies suggest the LIPUS does not affect the remodelling phase of fracture healing, but the earlier inflammatory or callus formation phases of healing and mainly the endochondral ossification, as well as the angiogenesis phase. Positive effects of LIPUS treatment on the maturation process of the bone regenerate during distraction osteogenesis have also been found in animal models, with significantly more callus formation, higher mineral content, and a higher bone regenerate stiffness. ${ }^{16,17}$ Recently, it has been shown that the effects of LIPUS are even more pronounced when applied during the lengthening phase compared to the maturation phase and that possibly its effect is mediated via endochondral pathways. ${ }^{18}$

The effect of LIPUS on periodontal ligament regeneration has also been reported. It has been observed that LIPUS induces early cementoblastic differentiation of human immature cementoblasts from the periodontal ligament by promoting the formation of substrate and increasing alkaline phosphatase(ALP) activity, enabling the regeneration of periodontal tissue destroyed by periodontal disease and the acceleration of the repair of root resorption.() Mostafa et al. demonstrated that ALP and OPN expressions were also induced in human gingival fibroblasts treated with LIPUS, confirming that after 3 weeks of $5 \mathrm{~min} /$ day exposure the osteogenic differentiation potential was enhanced. It has also been observed that LIPUS simulation significantly up-regulated COX-2 mRNA expression and enhanced PGE production inducing cementoblastic differentiation and matrix mineralization through EP2/EP4 prostaglandin receptors pathway. ${ }^{11}$

The use of LIPUS as a measure of accelerating the tooth movement in orthodontic patients has not been studied according to indexed literature. This is very important in the purview that orthodontic treatment is a time consuming procedure and the use of aids in accelerating the same would be ideal. Further, the available modalities have various compliance issues and side effects associated with them. Therefore, this study will be used to establish whether LIPUS can be used as a modality in accelerating the orthodontic tooth movement. The Objective of the present work are:

$>$ To assess the rate of orthodontic tooth movement with normal mechanics.

$>$ To assess the role of LIPUS in accelerating tooth movement in orthodontic patients.

$>$ To compare the rate of tooth movement with and without addition of LIPUS therapy.

\section{Material And Methods:-}

This prospective longitudinal case-control study was performed on thirty young adult patients undergoing fixed orthodontic treatment. The study was performed in the Department of Orthodontics, Nobel Medical College and Teaching Hospital Pvt. Ltd, Biratnagar, Nepal after obtaining ethical approval from the Nepal Health Research Council (NHRC, Kathmandu, Nepal). Thirty patients between the age group 18-30 requiring extraction of both maxillary first premolars followed by canine retraction were included in this study. Patients with any systemic illness, on medications (that interfere with tooth movement \& periodontal health) were excluded from this study. Informed consent was obtained from all the study participants. 
The orthodontic treatment was started using the standard treatment protocol. The left maxillary quadrant was considered as control whereas in the right maxillary quadrant LIPUS was applied at 2 week appointments. The amount of space closure will be calculated in both the quadrants at three different times viz T0 (just after bonding of orthodontic brackets), T1 (one month after initiation of treatment) and T2 (three months after initiation of treatment). The results were tabulated and statistically analysed.

\section{Results:-}

The amount of canine retraction as measured at three different time intervals shows that LIPUS has a positive effect on the degree of tooth movement. The distance of canine retraction was measured in relation to the first molar, the lateral incisor and the incisive papilla in both the LIPUS and the control groups. Graph 1 shows the difference in the canine retraction as measured between T0 \& T1 in both the groups.

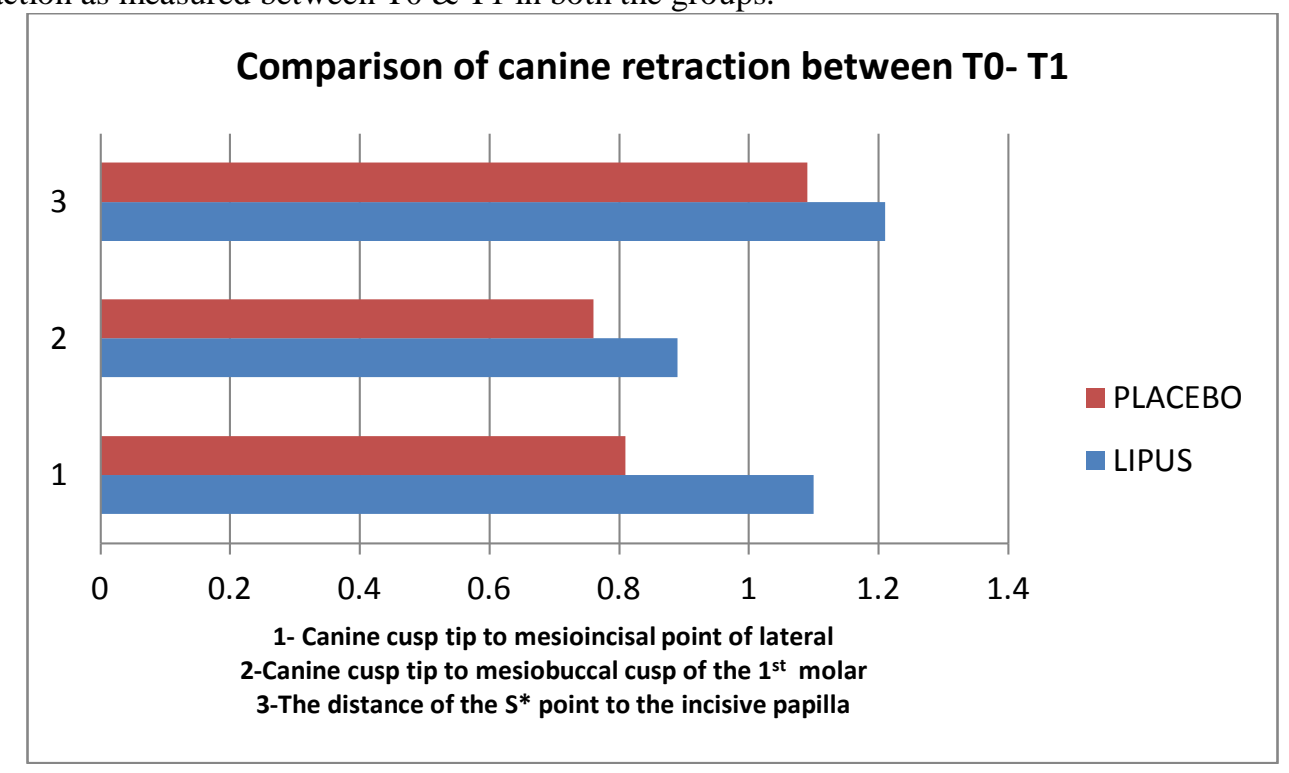

The distance of canine retraction as measured with respect to the first molar, lateral incisor and incisive papilla showed significant difference $(\mathrm{p}=0.001 ; \mathrm{p}=0.04 \& \mathrm{p}=0.02$ respectively) between the LIPUS \& the control groups between $\mathrm{T} 0$ \& $\mathrm{T} 1$.

Similarly, a significantly increased amount of canine retraction was observed due to LIPUS in comparison to the control group as evidenced by the three measurements $(\mathrm{p}=0.03 ; \mathrm{p}=0.02 \& \mathrm{p}=0.003)$ respectively between $\mathrm{T} 1$ and $\mathrm{T} 2$ (Graph 2). Also, the measurement of canine retraction when compared between T0 and T2 showed a significant difference for measurements made in relation to the first molar, lateral incisorand incisive papilla $(\mathrm{p}=0.001 ; \mathrm{p}=0.032$ $\& \mathrm{p}=0.006$ ) respectively (graph 3 ). 

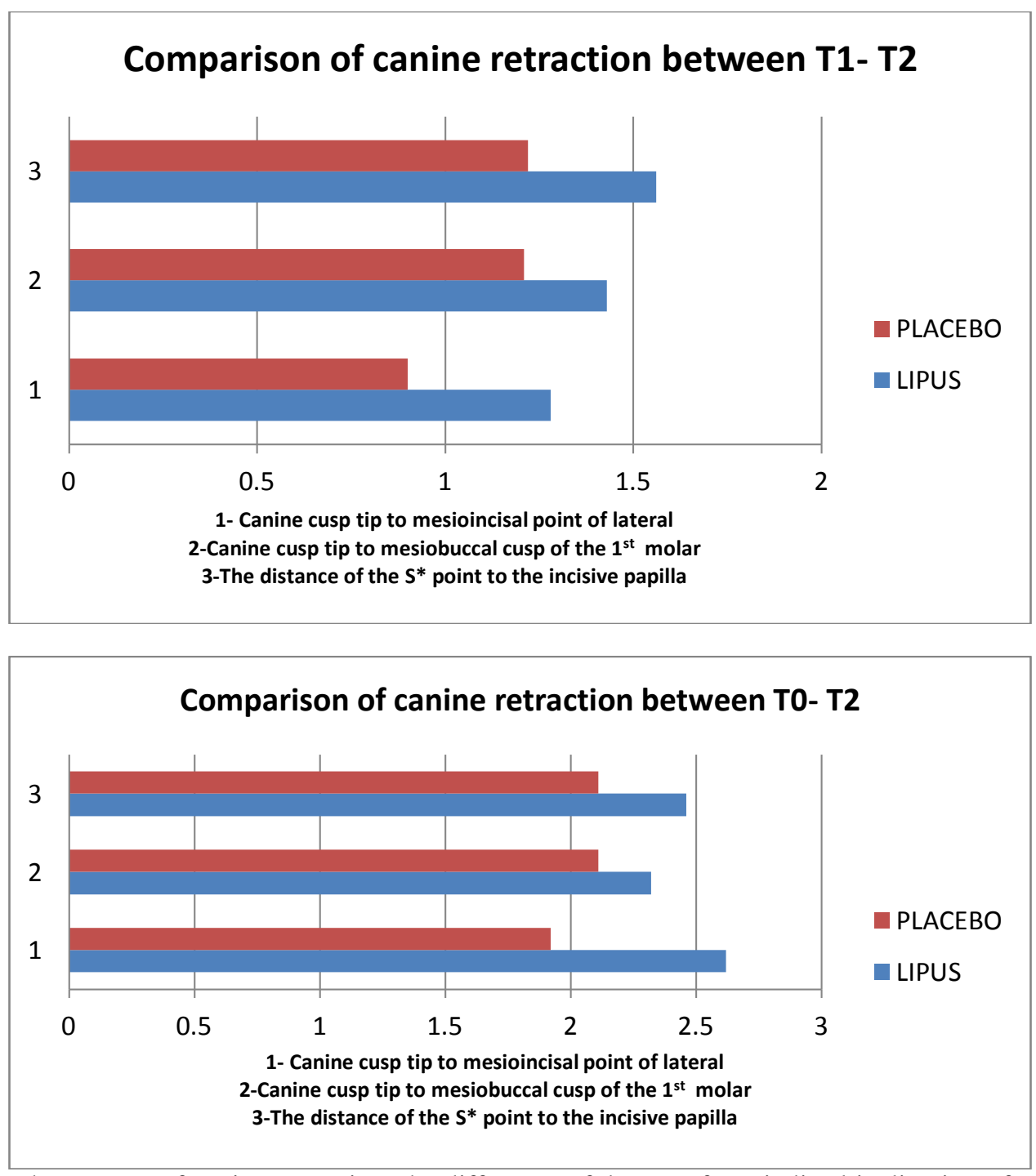

In addition to the amount of canine retraction, the difference of degree of mesiodistal inclination of canines where statistically analysed between the LIPUS group and the control group. Student's t-test was performed for comparing the difference in the mesiodistal inclination at various time intervals (T0\&T1; T1\& T2; T0 \& T2). It was observed that there was no statistically significant difference in mesiodistal inclination of canine due to LIPUS ( $p>0.05)$. The results are depicted in Table: 1 .

Table 1:-

\begin{tabular}{|l|l|l|c|l|l|l|}
\hline & \multicolumn{2}{|c|}{ T0-T1 } & T1-T2 & \multicolumn{2}{c|}{ T0-T2 } \\
\cline { 2 - 7 } & Mean & SD & Mean & SD & Mean & SD \\
\hline LIPUS & 1.96 & 2.25 & 1.02 & 2.26 & 2.13 & 3.21 \\
\hline Placebo & 2.01 & 3.02 & 1.22 & 3.72 & 2.13 & 2.12 \\
\hline P-value & $\mathbf{0 . 5 2 1}$ & $\mathbf{0 . 4 3 2}$ & $\mathbf{0 . 3 9 2}$ \\
\hline
\end{tabular}

Descriptive statistics and the results of student t-test analysis for comparison of the difference in mesiodistal inclination of canines (degree) between the low intensity pulsed ultrasound and placebo groups at the different treatment intervals.

\section{Discussion:-}

Shortening the duration of orthodontic treatment is a desirable goal for both the patients and the orthodontists. Various researches have been conducted in this regard with different modalities being tried and tested. ${ }^{19}$ These 
include pharmacological techniques to surgical interventions which have been used to accelerate the rate of orthodontic tooth movement. These, however have their own advantages and disadvantages. ${ }^{5,20,21}$ The need for noninvasive means of accelerating the orthodontic tooth movement have led to the use of laser and ultrasound in low intensities. $^{22}$

Low-intensity pulsed ultrasound (LIPUS) stimulation is a clinically established, widely used and FDA (Food and Drug Administration) approved intervention for accelerating bone growth during healing of fractures, non-unions and other osseous defects. Therapeutic ultrasound is also widely used, especially in sports medicine and myofunctional therapy, to decrease joint stiffness, reduce pain and muscle spasms, and improve muscle mobility. ${ }^{23}$ The effect of LIPUS on bone healing and regeneration of periodontal ligament have been studied extensively in various in vivo and in vitro studies. ${ }^{24,25,26}$ The mechanism of increased rate of fracture healing is still unclear. However, various studies indicate that LIPUS accelerates the differentiation pathway of mesenchymal stem cells in the osteogenic lineage via activated phosphorylation of mitogen-activated protein kinase pathway, up-regulation of cyclo-oxygenase-2, prostaglandin E2 and stimulating the bone morphogenetic proteins. ${ }^{27,28,29}$ Similarly different studies indicated that ultrasound has beneficial effect on the regeneration of soft tissues including periodontal ligament cells. ${ }^{30,31}$

The use of LIPUS in accelerating orthodontic tooth movement is limited with one study conducted on rats indicating a positive effect of LIPUS in this regard. ${ }^{32}$ Similar results have been observed in our study where routine use of LIPUS showed a significantly increased rate of $(\mathrm{p}<0.05)$ tooth movement as compared to the non LIPUS treated side. Xue $\mathrm{H}$ et al suggested that LIPUS stimulation caused an elevation of HGF/Runx2/BMP-2 Pathway gene expression and RANKL expression which caused an accelerated rate alveolar bone remodelling resulting in the orthodontic treatment duration. ${ }^{32}$

In this study, the degree of canine retraction was studied using three different parameters similar to the study done by Heravi $F$ et al who evaluated the effect of low level laser therapy on orthodontic tooth movement. ${ }^{33}$ All the three parameters in our study suggested a positive effect of LIPUS in accelerating orthodontic tooth movement.

This study also evaluated the difference in mesiodistal inclination of canine during the tooth movement. No significant difference was observed between the LIPUS and the control groups ( $>>0.05)$. Heravi et al suggested that the degree of tooth tipping is related to the extent of tooth movement and also the resistance offered by the alveolar bone towards tooth movement. An increased tip is said to be related to increased tooth movement. ${ }^{33}$ In our study, even though the tooth movement increased following treatment with LIPUS the tipping was not significantly altered.

\section{Conclusion:-}

Based on the above results, it can be assumed that LIPUS can be used as an effective means of accelerating tooth movement in fixed orthodontic patients and thereby reducing the treatment duration.

\section{Refreences:-}

1. Tamizharasi and Kumar S. Evolution of orthodontic brackets. JIADS 2010; 1(3): 25-30.

2. Diravidamani K, Sivalingam SK, Agarwal V. Drugs influencing orthodontic tooth movement: an overall review. J Pharm Bioallied Sci. 2012; 4(2): S299-S303.

3. Ren Y, Maltha JC, Van't Hof MA, Kuijpers-Jagtman AM. Optimum force magnitude for orthodontic tooth movement: a mathematic model. Am J Orthod Dentofacial Orthop. 2004; 125: 71-77.

4. Yamasaki K, Mirura F, Suda T. Prostaglandin as a mediator of bone resorption induced by experimental tooth movement in rats. J Dent Res. 1980; 59: 1635-1642.

5. Yamamoto TT, Kawakami M, Kobayashi Y, Yamashiro T, Sakuda M. The effect of local application of 1,25dihydroxycholecacliferol on osteoclast numberin orthodontically treated rats. J Dent Res.1992; 71: 53-59.

6. Spadoro JA. mechanical and electrical interactions in bone remodeling. bioelectromegnatics 1997; 18: $193-202$.

7. Hadjiargyrou M, McLeod K, Ryaby JP, Rubin C. Enhancement of fracture healing by low intensity ultrasound. Clin Orthop. 1998; 77(1): 14-32.

8. Nelson TR, Fowlkes B, Abramowicz JS, Church CC. Ultrasound Biosafety Considerations for the Practicing Sonographer and Sonologist. J Ultrasound Med. 2009; 28: 139-150.

9. Scheven BA, Man J, Millard JL, Cooper PR, Lea SC, Walmsley, AD, Smith AJ. VEGF and odontoblast-like cells: stimulation by low frequency ultrasound. Archives of Oral Biology 2009; 54(2): 185-191. 
10. Ter Haar G. Therapeutic ultrasound. European Journal of Ultrasound 1999; 9(1): 3-9.

11. Mostafa NZ, Uludag H, Dederich DN, Doschak MR, El-Bialy TH. Anabolic effects of low-intensity pulsed ultrasound on human gingival fibroblasts. Archives of Oral Biology 2009; 54: 743-748.

12. Rego EB, Takata T, Tanne K, Tanaka E. Current status of low intensity pulsed ultrasound for dentl purposes. The open dentistry journal 2012; 6(1): 220-225.

13. Borsje MA, Ren Y, de Haan-Visser HW, Kuijer R. Comparison of low-intensity pulsed ultrasound and pulsed electromagnetic field treatments on OPG and RANKL Expression in human osteoblast-like cells. Angle Orthodontist 2010; 80(3): 498-503.

14. Aonuma H, Miyakoshi N, Kasukawa Y, Kamo K, Sasaki H, Tssuchie H, Seagwa T, Shimada Y. Combined treatment of alendronate and low-intensity pulsed ultrasound (LIPUS) increases bone mineral density at the cancellous bone osteotomy site in aged rats: A preliminary study. J Nepal Med Assoc. 2011; 51(181): 171-175.

15. El-Bialy TH, Elgazzar RF, Megahed EE, Royston TJ. Effects of Ultrasound Modes on Mandibular Osteodistraction. JDR. 2008; 87(10): 953-957.

16. Esenwein, S. A. et al. Efficiency of low-intensity pulsed ultrasound on distraction osteogenesis in case of delayed callotasis - clinical results. Zentralbl Chir. 2004; 129(5): 413-420.

17. Takeuchi R, Ryo A, Komitsu N, Takagaki YM, Fukui A, Takagi Y et al. Low-intensity pulsed ultrasound activates the phosphatidylinositol 3 kinase/Akt pathway and stimulates the growth of chondrocytes in threedimensional cultures: a basic science study. Arthritis Research \& Therapy 2008; 10(4): 1-11.

18. Khanna A, Nelmes RT, Gougoulias N, Maffulli N, Gray J. The effects of LIPUS on soft-tissue healing: a review of literature. Br Med Bull. 2009;89:169-82.

19. Andrade Jr I, dos Santos Sousa AB, Gonçalves da Silva G. New therapeutic modalities to modulate orthodontic tooth movement. Dental Press J Orthod.2014; 19(6): 123-33.

20. Young L, Binderman I, Yaffe A, Beni L, Vardimon AD. Fiberotomy enhances orthodontic tooth movement and diminishes relapse in a rat model. Orthod Craniofac Res.2013; 16(3): 161-168.

21. Yuan H, Zhu X, Lu J, Dai J, Fang B, Shen SG. Accelerated orthodontic tooth movement following le fort I osteotomy in a rodent model. J Oral Maxillofac Surg.2014;72(4): 764-772.

22. FÁVARO-Pípi E, Feitosa SM, Ribeiro DA, Bossini P, Oliveira P, Parizotto NA, Renno AC. Comparative study of the effects of low-intensity pulsed ultrasound and low-level laser therapy on bone defects in tibias of rats. Lasers Med Sci.2010; 25(5): 727-732.

23. Dyson M. Therapeutic applications of ultrasound. in: nyborg wl, ziskin mc, EDITORS. Biological effects of ultrasound. New York: Churchill Livingstone; 1985; 121-33

24. Kristiansen TK, Ryaby JP, McCabe J, Frey JJ, Roe LR. Accelerated healing of distal radial fractures with the use of specific, low-intensity ultrasound. A multicenter, prospective, randomized, double-blind, placebocontrolled study. J Bone Joint Surg Am.1997; 79(7): 961-73.

25. Maddi A, Hai H, Ong ST, Sharp L, Harris M, Meghji S 2006, Long wave ultrasound may enhance bone regeneration by altering OPG/RANKL ratio in human osteoblast-like cells. Bone 2006; 39(2): 283-8.

26. Suzuki A, Takayama T, Suzuki N, Kojima T, Ota N, Asano S, et al. 2009, DAILY Lowintensity pulsed ultrasound stimulates production of bone morphogenetic protein in ROS 17/2.8 cells. J Oral Sci.2009; 51(1): 29-36.

27. Angle SR, Sena K, Summer DR, Virdi AS. Osteogenic differentiation of rat bone marrow stromal cells by various intensities of low-intensity pulsed ultrasound. Ultrasonics 2011; 51(3): 281-288.

28. Wang JH, Thampatty BP. An introductory review of cell mechanobiology. Biomech Model Mechnobiol.2006; 5(1): 1-16.

29. Ikeda K, Takayama T, Suzuki N, Shimada K, Otsuka K, Ito K. Effects of lowintensity pulsed ultrasound on the differentiation of C2C12 cells. Life Sci.2006; 79(20): 1936-1943.

30. Harle J, Salih V, Mayia, F, Knowles JC, Olsen I. Effects of ultrasound on the growth and function of bone and periodontal ligament cells in vitro. Ultrasound in Medicine \& Biology 2001; 27(4): 579-586.

31. Ikai H, Tamura T, Watanabe, Itou M, Sugaya A, Iwabuchi S, Mikuni-Takagaki Y, Deguchi S. Low-intensity pulsed ultrasound accelerates periodontal wound healing after flap surgery. Journal of Periodontal Research 2008; 43(2): 212-216.

32. Xue H, Zheng J, Cui Z, Bai X, Li G, Zhang C, He S, Li W, Lajud SA, Duan Y, Zhou H. Low-Intensity Pulsed Ultrasound Accelerates Tooth Movement via Activation of the BMP-2 Signaling Pathway. Plos One 2013; 8(7): e68926.

33. Heravi F, Moradi A, Ahrari F. The effect of low level laser therapy on the rate of tooth movement and pain perception during canine retraction. OHDM. 2014; 13(2): 183-188. 